\title{
Mining's seven questions to sustainability: from mitigating impacts to encouraging contribution
}

\author{
Anthony Hodge Consultants Inc. 231, Terrasse Barret, L'Assomption, Quebec, Cannada J5W 1M4; International Institute for Sustainable \\ Department, Winnipeg, Manitoba, Canada.
}

\begin{abstract}
A recent initiative emerging from the mining industry has led to development of a practical, robust, and quite widely applicable way of assessing contribution to sustainability that has come to be known as the Seven Questions to Sustainability (7QS). It is applicable at both the project level and for assessments covering the full mix of human activities within broad regions. It is sensitive to local values and site-specific conditions. In short, it amounts to providing a pragmatic and broadly applicable definition of "sustainability". This paper describes the foundation and nature of the $7 Q S$ approach, describes four applications, and draws out a set of observations relevant to the geoscientist.
\end{abstract}

\section{Introduction}

The debate about bringing theories of sustainable development and sustainability to practical application has continued ever since the 1987 publication of the report of the World Commission on Environment and Development or Brundtland Commission. They challenged the world to embark on a way of development that:

... meets the needs of the present without compromising the ability of future generations to meet their own needs ... not a fixed state of harmony, but rather a process of change in which exploitation of resources, the direction of investments, the orientation of technological development, and institutional change are made consistent with future as well as present needs ... not only a new era of economic growth for nations in which the majority are poor, but also an assurance that those poor get their fair share of the resources required sustaining that growth. (WCED, 1987, pp. 8, 9)

Complementing the Bruntdland Commission's sense of sustainable development, the idea of "sustainability" is a simple idea that involves the maintenance of certain necessary or desired characteristics of human society and the ecosystem (modified from Robinson et al., 1990).*

A recent initiative emerging from the mining industry has led to the development of the Seven Questions to Sustainability (7QS) assessment template, a practical, robust, and surprisingly generic method for tracking change over time while simultaneously providing a means for testing compatibility with sustainability concepts. By opening this assessment door, a definition of sustainabil- ity de-facto emerges that is broadly applicable and sensitive to local values and site specific conditions.

The focus on applying the 7QS approach is not so much on how mining can be sustainable - mining as a discrete activity cannot continue indefinitely - but on how mining can contribute to sustainability. Thus, the approach centres on a conceptual shift from analysis and mitigation of "impacts" to analysis and encouragement of "contribution." The purpose of this paper is to describe the 7QS approach and demonstrate its application.

This discussion is particularly germane to the geoscientist for three reasons. First, the geoscientist works in many different roles including mineral, oil, coal exploration and development, water resources, engineering geology, and a broad range of economic development applications. Almost always, these roles are at the interface between people and ecosystems. It is here that the application of sustainability ideas is most poignant.

Second, geoscientists have a familiarity with temporal and spatial scales that govern ecosystem functions - scales that are often discordant with human society's decision-making perspective. De Mulder, Eduardo F. J. and Umberto Cordani (1999) and Cordani (2000) have previously pointed this out in the context of a discussion on the importance of the geoscience-sustainability relationship. Bringing to bear this familiarity at a time when ecosystem understanding remains at an early stage is exceedingly important.

Third, the formation of geoscientists includes the development of a capacity to build insights based on a rigorous synthesis of data and information that is both qualitative and quantitative in nature. Given the degree of complexity of the human-ecosystem relationship and the large amount of uncertainty that prevails, it is only through such a synthesis that the greatest support for improved decision-making can be provided.

\section{The Seven Questions to sustainability assessment approach}

\section{Multidisciplinary origins}

In the broad sweep of history, trying to capture the nature of change over time has been a topic of interest since the time of the ancient Chinese. However, the last half of the 20th century saw an increasing focus on tracking change through formal compilation of measured "indicators." Much influenced by the events of the Depression, systems of national accounts were established in most countries immediately after WW II. Partly in reaction to this, the 1950s and

*Translation of these ideas into other languages has been a significant challenge. For example, the common translation of "sustainable development" into French has been "développement durable". If the French phrase had been the original, translation back into English could possibly have resulted in "hard development." A more pleasing translation for the overall sustainability concept is "pérennité" an ancient French word that in English (perennial) brings with it an idea of lasting through all seasons, lasting long or forever. When this kind of issue is thought of in terms of the some 6,800 living languages of the world (SIL International, 2004), the magnitude of the difficulty becomes evident. 
1960s saw social indicators and quality-of-life indicators come of age.

In the late 1960s and early 1970s, Ministries of Environment were created in almost every country. An early task was the identification of key environmental indicators for tracking the state-of-theenvironment. The early reports of the US President's Council of Environmental Quality (Council of Environmental Quality, 19701990) provide an exceptional body of literature addressing almost every technical aspect of indicator development and use. Similar work on health, healthy communities, sustainable development, and corporate sustainable development followed.

Most recently a special focus on "geoindicators" has emerged. Geoindicators are "measures of surface or near-surface geological processes and phenomena that vary significantly over periods of less than 100 years" (Berger and Iams, 1996). They address what has been a significant gap in typical state-of-environment and healthy community reporting work.

A key development in this train of events occurred in November 1996 when an international group of 24 assessment experts was convened at the Rockefeller Foundation's Study and Conference Centre in Bellagio, Italy under the auspices of the International Institute for Sustainable Development (IISD). The result was an overarching "Bellagio Principles for Assessment" aimed at providing a concrete link between the theory and practice of sustainable development (Hardi and Zdans, 1996).

All of this activity is summarized in Figure 1. Each of nine recognizable bodies of literature that correspond to the focus areas mentioned above is plotted over time.

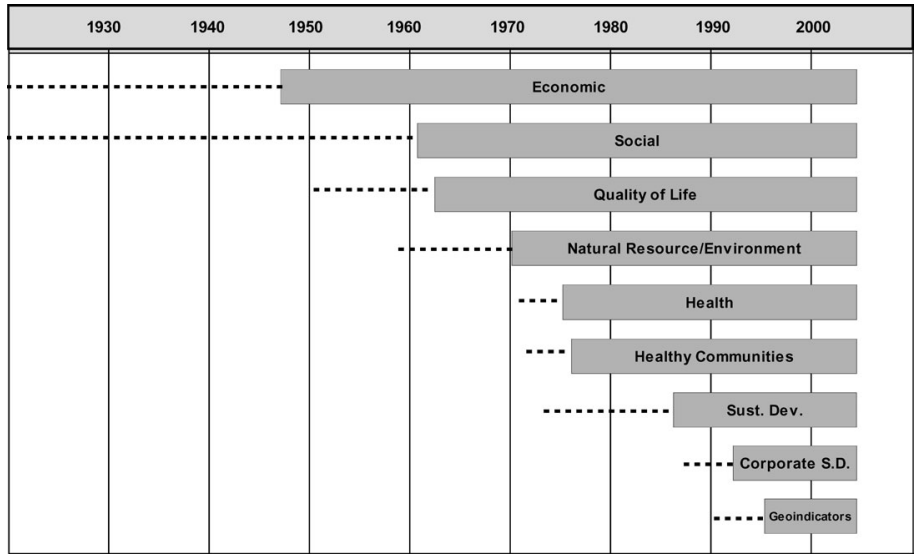

Figure 1 The span of the late 20th century literature on indicators (modified from Hodge 1995, 1997).

As can be seen from Figure 1, the banner of sustainable development is a relatively late arrival on the scene. Publication of the 1987 WCED report marked the "official" beginning of sustainable development activity. Echoing the concern of many, the Brundtland Commission called for new ways to measure progress, ways that would go beyond economic signals and capture a fuller sense of human and ecological well being (WCED, 1987). Five years later, the United Nations Conference on Environment and Development (Earth Summit) at Rio de Janeiro, Brazil produced its Agenda 21 (UNCED, 1992), which again called for new ways of tracking progress that would entrench the concept of sustainable development in practice, not just theory.

On the corporate side, response to the ideas of sustainable development followed quite quickly. Corporate environmental policies which had emerged in the late 1980s took on a sustainable development theme by the mid-1990s. A number of mining companies including Placer Dome, Noranda, and Rio Tinto played a leading role in this transition. By the early 2000's, corporate social responsibility had been added to the mix and something like "health, safety, environment, and community" or "safety and sustainability" now seem to be the kind of labels that are being used for the sustain- ability set of topics (see for example, BHP Billiton, 2002 and Placer Dome, 2004).

This cursory review spans a tremendous effort to enhance society's capacity to track change and feed decision-making in a useful way. However, in spite of much progress, the challenge of developing a systemic approach that brings together the many threads of needed knowledge in a practical lens that can be used to identify and assess change over time has remained elusive.

Over the past 15 years, the mining industry in particular, has found itself in a particularly difficult and unprecedented period of transition (Mining Minerals and Sustainable Development, 2002a):

A broad array of interrelated technical, environmental, and social issues face the mining/minerals community. Legal and financial implications have multiplied as investors, indigenous people, communities, non-governmental organizations and other interests apply increasing scrutiny to mining operations. With the immediacy of worldwide communications, local incidents become global news overnight.

In short, the mining industry remains under great pressure to improve practices and demonstrate a positive response to the imperatives of sustainable development. Part of its response has been to develop new systems to recognize, track, record, and understand change. It is doing so to: (1) facilitate continuous learning and improve decision-making; (2) provide early warning signals for needed changes in policy, behaviour, or infrastructure thus reducing risk; (3) encourage innovation, creativity, and pride by recognizing and celebrating success; (4) promote accountability by reporting on whether or not commitments have been discharged; and (5) identify and prioritize gaps in knowledge so that the limited available resources can be put to work first on topics that are the most pressing (modified from NRTEE, 1993 and Hodge, 1996).

Through 2001 and 2002, the author served as facilitator of the Mining Minerals and Sustainable Development (MMSD) - North America project, an independent regional component of a global review of mining practices undertaken by the International Institute for Environment and Development (London) on behalf of the World Business Council for Sustainable Development (Geneva).

As part of its work, MMSD - North America convened a Work Group of 35 people reflecting a broad range of interests from across society (industry, indigenous peoples, government, environmental and social non-government organizations, academia). The group was charged with developing a set of practical principles, criteria and/or indicators that could be used to guide or test mining/minerals activities in terms of their compatibility with concepts of sustainability. The full mining-project life-cycle shown in Figure 2 was adopted to guide the work.

The exercise was motivated by the need to identify, assess, and communicate change in a way that would be equally meaningful to explorer, mine manager or mill superintendent. In short, their chal-

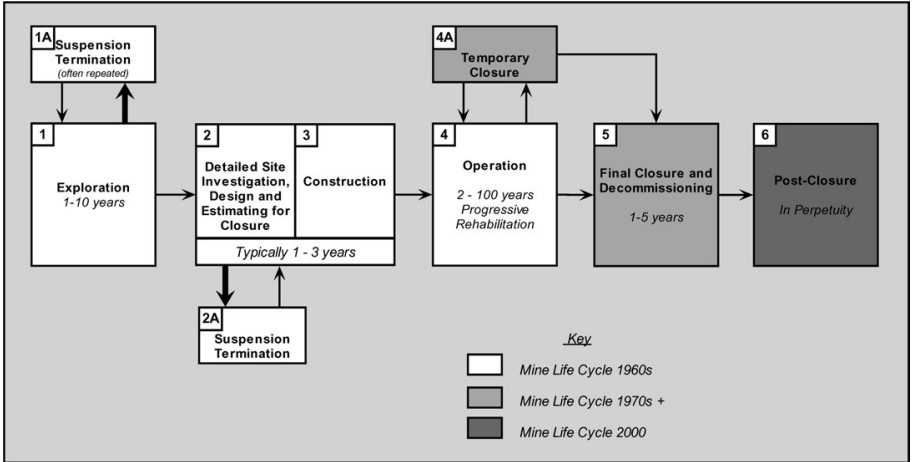

Figure 2 The Full Mine Project Life-Cycle. Up until the 1960s, little thought was given to activities beyond the operational phase. In the 1970s, the need for decommissioning and surface reclamation was recognized. Only in the last few years has attention been given to the human and ecological implications of the post-closure period (modified from John Gadsby, personal communication and Hodge, 2001b). 
lenge was to come to grips with a practical application of the sustainability concept.

Work on this front began with a review of 10 recent initiatives from a broad range of perspectives including: (1) international investment (West and Tarazona 2001), (2) the mining industry (Rio Tinto Borax 2001; Alcan 1999), (3) work on Inco's massive Voisey's Bay project in Labrador and commissioned by local indigenous people (Green 1998), (4) environmental non-government organizationcommissioned work related to review of the Tulsequah Chief mine in British Columbia (Green 2001); (5) sustainability and environmental assessment (Canadian Environmental Assessment Agency 1999; Gibson 2002; Hodge 2001b), and (6) government (NRCan 2000; US Sustainable Minerals Roundtable 2001).

Authors of eight of these contributions participated in the Work Group. In addition, many of the participants had direct involvement with the literature described earlier in this section. The overall result was an unprecedented opportunity to collaboratively develop an innovative assessment template built on a vast, existing base of knowledge from a broad range of disciplines and interests.

\section{Conceptual foundations}

A number of important conceptual underpinnings provide the foundation for this work. The key elements are described below (summarized from MMSD North America, 2002b, and Hodge, in press).

Value base, goal, and achieving a positive contribution. At the core of sustainability concepts lies a value set that is best stated as "parallel care and respect for the ecosystem and people within." From this value set follows the goal of sustainability: to achieve human and ecosystem well being together. In other words, the success of a mine (or any human activity) should be judged in terms of its contribution to human and ecosystem well being together. From the perspective of "results-based management" this is the result to be tested for.

Such a "positive contribution to sustainability" criterion is different from, though built upon, the "mitigation of adverse effects" criterion that is the focus of traditional environmental, social, and economic impact assessments. There are two important implications. First, it may be tougher to demonstrate positive contribution than to identify and mitigate impacts. However second, by taking this direction, a fairer treatment of both positive and negative implications is facilitated than has typically been encouraged through traditional social, environmental, and economic impact analyses (see Gibson, 2000 for a full discussion of this change) and better decision-making results.

Seen in this way, the concept of sustainability is much more than environmental protection in another guise. It is a positive concept that has as much to do with achieving well being for people and ecosystems as it has to do with reducing stress or impacts (Hodge and Taggart 1992, NRTEE 1993, Hodge et al.1995, Hodge 1995, Prescott-Allen 2001).

Moving away from a perspective of environment vs. people. These ideas veer sharply away from thinking in terms of a "tradeoff" between human and ecosystem well being. There are obviously many small trade-offs in any practical application: between interests, between components of the ecosystem, across time, and across space. However, in an overarching sense, the idea of sustainability calls for both human and ecosystem well being to be maintained or improved over the long term. Maintaining or improving one at the expense of the other is not acceptable from a sustainability perspective because either way, the foundation of life is undermined.

Respecting differences in perspective between the developing and developed worlds. In practical application, expression of the sustainability duality - human plus ecosystem well being - is very culture-dependent. In the developed world, the past 30 years have seen environmental values grow to be a strong influence in many decision-making processes. Environmental assessment and protection are accepted practices; resources are put to these considerations and at least some thought is given to the implications of today's action for future generations even though consumption patterns remain problematic. In contrast, hunger, poverty, and poor health are often the driving forces and ethical imperatives in much of the developing world. The urgency of putting resources to feed, clothe, house, and provide health care for those now living is simply too great to allow much emphasis on the needs of those not yet born. These developing and developed world perspectives are not mutually exclusive. However, simultaneous expression of both without care and sensitivity can and does lead to tension.

Dealing with the integrity of how we act as well as the substance of what we do. Because "sustainability" involves the maintenance of certain necessary or desired characteristics of human society and/or the ecosystem, decisions must be made about what is necessary or desired. Making such decisions is a value-based process that will depend on who is deciding. When more than one set of values is implicated, the process of resolving value-based differences becomes critically important. Therefore, in bringing ideas of sustainability from theory to practice, the process of application (the how) is as critical as the substance of the application (the what).

Achieving security. The approach to implementing sustainability concepts reflected in this discussion aims to re-establish a sense of confidence that:

- people can and will have an opportunity to participate in the decisions that affect their future;

- resources will be made available to ensure individuals and communities will have the capacity and resources to participate in the decisions that affect their future;

- acceptable outcomes will be achieved not only during a mine operation but also after closure;

- all interests including companies, governments and others will fulfill the commitments that they make regarding human (social, cultural, economic) and ecological conditions; and

- expectations across interests can be more effectively aligned throughout the full project life cycle from exploration through post-closure.

Together, the above elements amount to creating a sense of security and faith in the future-whether it is from the perspective of a company, a community, or the ecosystem.

Seeing and designing mining as a "Bridging" activity. At any given site, mining (or smelting, refining, and primary metals manufacturing) has a beginning and an end. In that context, no mine/mineral activity is in itself, sustainable. However, the implications of that activity go on indefinitely - not only as a direct result of the activity but also through the product that is produced. In that sense, mining/mineral activities serve as a bridge to the future. They are not an end in themselves but a critical part of achieving longer term ends. Mine design should be undertaken with this bridging role as an explicit part of project design. Setting such a context explicitly broadens and lengthens the planning and decision-making conditions that govern mine implementation. Simultaneously, it aligns the design process with systems thinking and the principles of industrial ecology.

\section{The 7QS template}

After much deliberation, the Work Group identified seven topics that were deemed essential for inclusion in any sustainability-driven assessment. For each of these, a question was crafted to be applied in any application. Together they form a template that came to be called the Seven Questions to Sustainability (7QS). The template in summary format is shown in Figure 3 and the questions are listed in detail in Table 1.

The 7QS approach really encompasses four categories of insight as follows.

1. Relationships. Question 1 (Engagement) deals with the state of relationships that are important to any given project or within any region that is being assessed (see Joyce and Thompson and Joyce, 2,000 for a succinct discussion of this topic). A key issue facing many projects is to address a sense that the distribution of costs, benefits, and risk is unfair. This sense can cause stake- 
holder reactions that range from feelings of discontent to outright civil disobedience and damage to persons and property. Although detailed procedures will vary from site to site, the 7QS approach calls for addressing this issue early and in a way that facilitates constructive relationships achieved through ensuring a fair distribution of costs, benefits, and risks over the full project life-cycle.

2. Ends. Questions 2 (People) and 3 (Environment) focus on the end results that must be achieved and against which the success of any project must be tested-human and ecosystem well being over the long-term.

3. Means to Achieving Ends. Questions 4 (Economy), 5 (Non-market activities) and 6 (Governance and Institutions) cover the various means of achieving human and ecosystem well being.

4. Feedback. Lastly, Question 7 (Synthesis and Continuous Learning) provides the feedback mechanism that allows people to both learn from the inevitable mistakes and to celebrate the successes, giving credit where it is due.

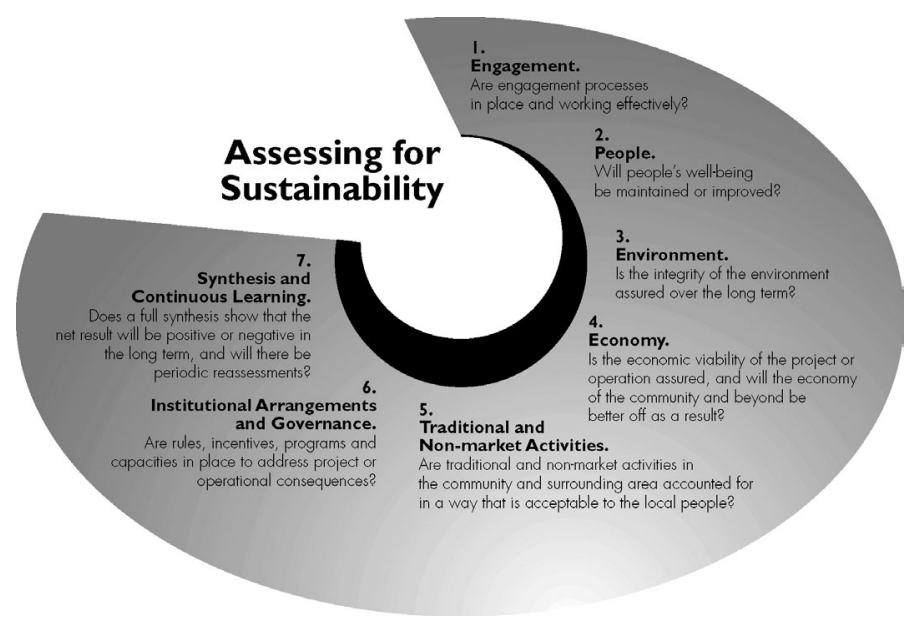

Figure 3 The Seven Questions to Sustainability (Source: $\mathrm{MMSD}$, North America, 2002).

From the Seven Questions falls a hierarchy of objectives, indicators and specific metrics. In this way a single, initial motivating question - is the net contribution to sustainability positive or negative over the long term? - cascades into progressively more detailed elements which can be tailored to the project or operation being assessed for application throughout its full life-cycle. Simultaneously, the starting point for assessing the degree of progress is provided by an "ideal answer" to each of the seven questions.

Potential uses of the assessment template include: (1) early project appraisal related to assessment for acquisition of a potential mining property and its feasibility for development; (2) overall project planning and identification of who should be involved and when; (3) thorough identification of risk as a basis for financing and insuring; (4) guidance for processes of licensing and approval; (5) internal corporate reviews of performance during operation; (6) guidance for corporate reporting to shareholders and others; and (7) guidance for external review of projects. In addition to project-level applications, the template has proven very effective for regional-level reviews of the mining activity in which the implications of a range of projects and conditions must be assessed.

\section{Persistent Contentious Issues}

A number of contentious issues remain to be addressed in any given application of the 7QS template. These include:

- The equity issue: detailed site-specific procedures for describing and addressing the distribution of costs, benefits, and risks amongst parties involved in the activity or project being reviewed;

- Trade-offs: designing and implementing optimum decision-making systems and approaches that effectively and fairly address trade-offs in any given site application;
- Need and alternatives: effectively and fairly assessing the need for a given project and/or commodity in light of considerations and alternatives that span local to global implications;

- Achieving a whole system perspective: seeing, understanding, and factoring in a sense of the whole system, not just the small component parts;

- Uncertainty, precaution, and adaptive management: dealing with uncertainty using an appropriate level of precaution and an adaptive management approach; and

- The attribution problem and dealing with cumulative impacts: addressing most effectively the common situation where a project is one of a number of contributors to social, cultural, economic, and environmental change or stress-establishing the cumulative implications, apportioning responsibility, and deciding who should take responsibility for the analysis.

These issues are not new. Many have grappled with them before and others will continue to work on them in the future as different approaches to their resolution are tried. Together, they are a testament to some of the complexities that must be faced in bringing the ideas of sustainability from theory to practice. A fuller discussion of these topics is provided in MMSD, 2002b.

In spite of these kinds of challenges, application of the 7QS approach has proven to be extremely useful. In the following section, four illustrative case studies are briefly described.

\section{Four case studies}

\section{Case 1. From strategy to action: sustainability and Tan Range Exploration corporation}

Tan Range Exploration is a Vancouver-based, 'publicly traded' gold company whose business strategy is to develop royalty income by way of property agreements with senior industry partners. All of their properties are in the Lake Victoria greenstone belt goldfields of Tanzania. At present, Tan Range holds 73 prospecting licenses, eleven of which fall under option agreements with Barrick Gold. Another nine projects are the subject of royalty agreements with Montreal-based Northern Mining Explorations.

Tan Range has developed a comprehensive policy on Social Responsibility (Sustainable Development) that begins with the statement: Our mission is to increase the known mineral resource base of Tanzania in a way that enhances the well being of its people, the environment, and the investors and stakeholders of Tan Range Exploration.

Guided by an analysis using the 7QS approach, a Sustainable Development program is presently being implemented that will enable the Company to leave a positive legacy in Tanzania. Future negotiating positions for new royalty agreements will include a provision whereby $1 \%$ of all royalty payments owed to Tan Range will be committed to social and development work within Tanzania. These payments will be the responsibility of the mine operator.

Tan Range aims to be a leader amongst exploration companies worldwide. To achieve this goal, it has recognized the competitive advantage of being able to pass on its properties to mine developers in full confidence that the foundation of geological information, social relationships and environmental conditions is fully understood and without hidden risks and liabilities. For further information see Tan Range, 2004.

\section{Case 2. Out of respect: The Tahltan First Nation, mining, and the seven questions to sustainabilty}

The Tahltan First Nation, an indigenous people whose traditional territory covers some $100,000 \mathrm{~km}^{2}$ in north western British Columbia, have been involved in providing services for mining exploration for well over 50 years. In the last 15 years they have 
Table 1 Detailed questions and sub-elements of the Seven Questions Assessment Framework.

\begin{tabular}{c|c}
\hline Question & Sub-elements \\
\hline $\begin{array}{c}\text { Engagement: Are processes of engagement committed } \\
\text { to, designed and implemented that: }\end{array}$ & 1.1 Engagement processes \\
* ensure all affected communities of interest (including vul- \\
nerable or disadvantaged sub-populations by reason of, for exam- \\
ple, minority status, gender, ethnicity or economic status) have the
\end{tabular}
opportunity to participate in the decisions that influence their own future; and

* are understood, agreed upon by implicated communities of interest and are consistent with the legal, institutional and cultural characteristics of the community and country where the project is located?

2. People: Will the project/operation lead directly or indirectly to maintenance of people's well being (preferably an improvement):

- during the life of the project or operation?

- in post-closure?

2.1 Community organizational capacity

$2.2 \mathrm{Social} /$ cultural integrity

2.3 Worker and population health

2.4 Availability of basic infrastructure

2.5 Direct, indirect and induced effects

2.6 Full social/cultural costs, benefits and risks

2.7 Responsibilities and sureties

2.8 Distribution of costs, benefits and risks

2.9 Social/cultural stress and restoration

3. Environment: Will the project/operation lead directly or indirectly, to the maintenance or strengthening of the integrity of biophysical systems so that they can continue in post-closure to provide the needed support for the well being of people and other life forms?

Economy: Is the financial health of the project/operation assured and will the project or operation contribute (through planning, evaluation, decision-making and action) to the long-term viability of the local and regional economy in ways that will help ensure sufficiency for all and provide specific opportunities for the less advantaged?

5. Traditional and non-market activities: Will the project/operation contribute to the long-term viability of traditional and non-market activities in the implicated community and region?

6. Institutional arrangements and governance: Are the institutional arrangements and systems of governance in place to provide a reasonable degree of confidence that the capacity to address project or operation consequences will continue to exist through the full life-cycle including post-closure?

7. Synthesis and continuous learning: Has an overall evaluation been made and is a system in place for periodic evaluation based on:

- consideration of all reasonable alternative configurations and designs at the project level (including the no-go option in the initial evaluation);

- consideration of all reasonable alternatives at the overarching strategic level for supplying the commodity and the services it provides for meeting society's needs; and

- a synthesis of all the factors raised in this list of questions, leading to an overall judgment that the contribution to people and ecosystems will be net positive over the long term?
3.1 Ecosystem function, resilience, and self-organizing capacity

3.2 Ecological entitlement

3.3 Full ecosystem costs, benefits and risks

3.4 Responsibilities and sureties

3.5 Environmental stress and action to ensure ecosystem integrity
4.1 Project or operation economics
4.2 Operational efficiencies
4.3 Economic contributions
4.4 Community/regional economies
4.5 Government and broader society economies

$\begin{array}{ll}\text { 5.1 } & \text { Activity/use levels } \\ 5.2 & \text { Traditional/cultural attributes }\end{array}$

6.1 Efficiency and effectiveness in the mix of legislated rules, voluntary programs, market incentives and unspoken cultural norms

6.2 Capacity to address operational consequences

6.3 Bridging to post-closure conditions

6.4 Overall confidence that commitments made will be fulfilled

7.1 Project level alternatives

7.2 Strategic level alternatives

7.3 Overall synthesis

7.4 Continuous learning and improvement 
been increasingly active in mine development, mine closure, and post-closure monitoring and follow-up.

In the spring of 2003, they set out to: (1) assess the relationship between themselves, their land and the mining industry (exploration, operation and closure/post-closure); and (2) build a strategy to guide that relationship in the future. Seeking an outcome that would be beneficial for both themselves and the mining industry, they convened a multi-interest symposium involving the Tahltan people, government, and industry. The $7 \mathrm{QS}$ assessment framework was used to guide both the assessment process and design of the resulting "Tahltan Mining Strategy".

The Tahltan are anxious to signal support for mining as long as it respects their values and concerns. The 7QS provided a means to fairly and openly treat not only direct and indirect employment and local procurement of services but also more sensitive and difficult issues such as: (1) overall management/co-management of activities; (2) seeking a fair distribution (considering all participating interests) of all benefits, costs and risks; and (3) environmental conditions and the health/social/cultural implications of mining/mineral activity that continue to receive inadequate attention.

Full details are provided in Tahltan Nation and the International Institute for Sustainable Development, 2003.

\section{Case 3. Community-based collaborative forestry: Approach Apache-Sitgreaves National Forest, Arizona}

In 2002, a catastrophic fire destroyed some 732 square miles of the Apache-Sitgreaves National Forest in Arizona and caused loss of $\$ 500$ million in property including lost timber, insurance claims, and lost business from the evacuation of 30,000 people. The Apache-Sitgreaves has 34 lakes and reservoirs and more than 680 miles of rivers and streams - more than can be found in any other Southwestern National Forest. The White Mountains contain the headwaters of several Arizona rivers including the Black, the Little Colorado, and the San Francisco.

The cause of much of the fire damage is attributed to "unnatural" growth in the forest that has occurred as a result of human suppression of natural fire and disease processes. As a result, a plan has been created to undertake comprehensive thinning operations to cull small-diameter trees throughout the forest in order to return the ecosystem to health and reduce the impact of large wildfires. Such cutting in a National Forest is not without controversy, and the project has been carefully built to be consistent with principles of sustainability.

To undertake the work, a community-based company (the White Mountain Region Forest Restoration and Development Corporation) was created and approached the US Forest Service for support to undertake the work. The company is committed to engage key stakeholders to participate in the venture and oversee practices to ensure that operations maintain consistency with key economic, environmental, and social objectives. In addition, select stakeholders will serve as trustees of the White Mountain Forest Trust Foundation, a not-for-profit corporation created to address environmental and social issues within the region. The White Mountain Forest Trust Foundation will be financed by an annualized revenue stream from White Mountain Forestry Company's cutting operation.

In this case, confidence that the project would maintain consistency with sustainability concepts was provided by use of the 7QS approach to guide performance measurement and progress assessment. Details are found in Resource Science Inc., 2003.

\section{Case 4. Going beyond the Seven Questions: Towards a long-term approach for managing used nuclear fuel in Canada}

Canada currently has 22 licensed commercial nuclear power reactors that have produced some 1.7 million used nuclear fuel bun- dles in the 30 years since the first of these units was brought on line. Used and still highly radioactive nuclear fuel is currently stored beside the reactors in temporary facilities.

In November 2002, the Government of Canada passed legislation requiring the producers of used nuclear fuel in Canada to create a non-profit organization to: (1) undertake a review of alternatives and by November 2005 make a recommendation to the government on how Canada might best proceed to manage used nuclear fuel over the long term, and (2) assume responsibility for implementing the chosen management approach when the final decision is made by the government.

As a result, the Nuclear Waste Management Organization (NWMO) was created. It set out to develop collaboratively with Canadians a management approach for the long-term care of Canada's used nuclear fuel that is socially acceptable, technically sound, environmentally responsible and economically feasible. Consistent with the "polluter pay" principle, a process has been initiated to have the nuclear waste producers set aside the high level of funds required for implementation of the management approach that is ultimately chosen.

Over a dozen different technical methods have been suggested for consideration over the years. However, three are identified in the legislation for closer examination by NWMO: deep geological disposal in the Canadian Shield; storage at reactor sites; and centralized storage either above or below ground. Should there be good reason, the NWMO may consider approaches other than these three.

At the end of 2003, the NWMO released its first major discussion document, Asking the Right Questions? The Future Management of Canada's Used Nuclear Fuel (NWMO, 2003). The report outlines the results of an intensive and ongoing discussion with Canadians about their concerns and priorities. Building on the approach of the 7QS the NWMO chose to capture the concerns of Canadians in the form of the 10 questions summarized in Table 2.

The ten questions are now being used (spring 2004) as a foundation for the comparative analysis of alternative management approaches required in developing a recommendation for action to be put to the Government of Canada by mid-November 2005. These questions build upon and extend the $7 \mathrm{QS}$ template by addressing issues of particular concern relevant to the mandate and context of the NWMO (see Runnalls 2003). This kind of modification is essential for any given application.

\section{Discussion}

The greatest power of the concept of sustainability lies in its integrating capacity - its ability to provide a bridge between disciplines and interests, between the pieces of the whole and the whole itself. The 7QS assessment template provides a generic roadmap to facilitate this bridging. In any given application, region-, site- or projectspecific modifications may be appropriate. The following strengths of the 7QS approach can be identified.

-The breadth of the knowledge base that was used in its development. This is not a "new" stand-alone approach. Rather, it builds on decades of work in a large number of disciplines.

- Its grounding in an explicit value set combined with its systematic but pragmatic construction from that base.

- Its sensitivity to a range of values and site-specific conditions.

- Its balanced treatment of benefits and costs, positives and negatives.

- Its capacity to reveal the broadest range of risks for consideration by decision-makers.

- Its pragmatic approach to applying the ideas of sustainability. The 7QS assessment template provides an alternative door into describing the sustainability concept in practical terms.

-The breadth of potential applications and its potential for bringing consistency across applications.

The four case studies briefly described above, demonstrate a range of applications from corporate mining strategy development to 
Table 2 NWMO's ten questions that provide the foundation for comparative analysis of alternative approaches for the long term management of used nuclear fuel.

\section{Overarching Aspects}

Q-1. Institutions and governance. Does the management approach enjoy a fundation of rules, incentives, programs and capacities that ensure all operational consequences will be addressed over the long term?

Q-2. Engagement and participation in decision making. Does the management appropch provide for deliberate and full public engagementthrough different phases of the implementation?

Q-3. Aboriginal values. Have aboriginal spiritual, cultural and social values and insights been appropriciately identified, addressed, and integrated into the management approach?

Q-4. Ethical consideration. Is the process for selecting, assessing and implementing the management approach fair and equitable to our generation, and future generations?

Q-5. Synthesis and continuous learning. Does a synthesis of all factors lead to confidence that the management approach will contribute to an overall improvement in human and ecosystem well being over the long term; is a system proposed for periodic reassessment of all factors; and are ideas of continuous learning and improvement embedded in the proposed management approach?

\section{$\underline{\text { Social Aspects }}$}

Q-6. Human health, safety, and well being. Will the management approach ensure that people's health, safety, and well being are matained or improved now and over the long term?

Q-7. Security. Does this method of dealing with used nuclear fuel adequately contribute to human security and will the eventualresult adequately reduce access to nuclear materials by terrorists?

Environmental Aspects

Q-8. Environmental integrity. Will the management approach ensure that the integrity of the environment is assured over the long term?

\section{Economic Aspects}

Q-9. Economic viability. Is the economic viability of the management approach assured and will the economy of the community and beyound be maintained or improved as a result?

\section{Technical Aspects}

Q-10. Technical adequacy. Is the technical adequacy of the management approach assured and are design, construction and aperation of the method(s) used by the managemnet approach based application of the best available technical and scientific insight?

Source: NWMO, 2003

forestry and nuclear waste management. An emerging idea from these cases is that the kind of "contribution" analysis reflected in the $7 \mathrm{QS}$ approach is a natural evolution from traditional "impact" analyses that have predominated project assessment and regulation over recent decades. While the $7 \mathrm{QS}$ approach may initially seem tougher to apply and achieve success, it provides a fairer treatment of both positive and negative implications than has been possible with the traditional approach of impact analyses.

Application of the 7QS assessment template requires a capacity to bring together both quantitative and qualitative data and information. The past century has seen a increasing emphasis on the quantitative. However, there are limits to this kind of emphasis. Many years ago, Lewis Mumford voiced a concern for this evolution when he wrote (Mumford, 1934):

The new attitude toward time and space infected the workshop and the counting house, the army and the city. The tempo became faster, the magnitudes became greater; conceptually, modern culture launched itself into space and gave itself over to movement. What Max Weber called the "romanticism of numbers" grew naturally out of this interest. In time-keeping, in trading, in fighting, men counted numbers, and finally, as the habit grew, only numbers counted.

Even Albert Einstein added a note of caution with a sign hung on his Princeton office door that read not everything that can be counted counts and not everything that counts can be counted.

Geoscientists are trained to work rigorously with both qualitative and quantitative information, bringing together story and measurement to develop the best possible synthesis of knowledge. Application of the 7QS assessment template demands this kind of skill. However, more than ever before, these skill sets need to be exercised in the arena of public policy. There is thus a major challenge for the geoscientist: rarely is s/he comfortable in dealing with the "mixed drama, tragedy, and farce of the social process" (Checkland and Scholes, 1990, p. 31). As the complex mix of social, eco- nomic, and environmental pressures increase, this is an ongoing challenge that must be faced.

\section{Acknowledgements}

Many individuals contributed to the original development of the 7QS approach and the subsequent applications described in the paper. I am particularly appreciative of the contributions of all of the original members of the MMSD-North America Work Group and the International Institute for Sustainable Department staff who supported the effort. In preparing this paper, Tony Berger provided a thorough review for which I am very thankful.

\section{References}

Alcan, 1999. Alcan in BC -- Performance 1999. Montreal: Alcan Ltd. Available on-line at http://www.alcan.com.

Berger, Antony and William Iams (eds.), 1996. Geoindicators - Assessing Rapid Environmental Change in Earth Sciences. Rotterdam: A. A. Balkema. Available on-line at http://www.geoindicator.org.

BHP Billiton, 2002. Health Safety Environment and Community Report 2002. Melbourne Australia: BHP Billiton. Available on-line at http://www.bhpbilliton.com.

Canadian Environmental Assessment Agency (CEAA), 1999. Voisey's Bay Mine and Mill Environmental Assessment Panel Report, Chapter 2, The Project and Sustainable Development. Available on-line at http://www.ceaa.gc.ca/panels2/voisey/report/2_e.htm.

Checkland, Peter, and Jim Scholes, 1990. Soft Systems Methodology in Action. Chichester: John Wiley \& Sons.

Cordani, Umberto G., 2000. The role of the earth sciences in a sustainable world. Episodes 33: 3. pp. 155-160.

Council of Environmental Quality, 1970-1990. Annual Reports 1-20. Washington D.C.: Executive Office of the President. 
De Mulder, Eduardo F. J. and Umberto Cordani, 1999. Geoscience provides assets for sustainable development. Episodes 22: 2. pp. 78-83.

Gadsby, John. Personal Communication. Consulting Geotechnical Engineer, Vancouver and Hornby Island, British Columbia.

Gibson, Robert B., 2000. Favouring the Higher Test: Contribution to Sustainability as the Central Criterion for reviews and decisions under the Canadian Environmental Assessment Act. Journal of Environmental Law and Practice. 10:1, 39 - 54

2002. Specification of Sustainability-based Environmental Assessment Decision Criteria for Determining Significance in Environmental Assessment. Hull, Quebec: Canadian Environmental Assessment Agency.

Green, Thomas, L., 1998. Lasting Benefits from Beneath the Earth: Mining Nickel from Voisey's Bay in a Manner Compatible with the Requirements of Sustainable Development. Prepared for the Innu Nation.

Green, Thomas L., 2001. Mining and Sustainability: the case of the Tulsequah Chief Mine. Victoria: Environmental Mining Council of British Columbia.

Hardy, Peter and Terrence Zdans, 1997. Assessing Sustainable Development in Practice. Winnipeg: International Institute for Sustainable Development.

Hodge, R. Anthony., 1995. Assessing Progress Toward Sustainability: Development of a Systemic Framework and Reporting Structure. Ph.D dissertation, School of Urban Planning, Faculty of Engineering, McGill University, Montreal.

1996. A systemic approach to assessing progress toward sustainability. Chapter 10 in Dale, A, and J. B. Robinson, 1996. Achieving Sustainable Development. Vancouver: UBC Press.

, 1997. Toward a Conceptual Framework for Assessing Progress Toward Sustainability. Social Indicators Research 40: 5-98.

2001a. Mining: A Study in Sustainability and Change in the Knowledge Economy. Paper presented at the Conference: Building Canadian Capacity - Sustainable Production and the Knowledge Economy. Ottawa, April 4-5, 2001. Ottawa: Carleton Research Unit in Innovation, Science and Environment (CRUISE), Carleton University.

2001b. Sustainability and the Proposed Tulsequah Chief Project. Report prepared for the BC Environmental Assessment Office. Victoria: Anthony Hodge Consultants Inc.

2004. Tracking Progress toward Sustainability: Linking the Power of Measurement and Story. Paper presented at the Society for Mining, Metallurgy and Exploration (SME) Symposium: Sustainable Development from the Ground Up: Measuring Progress Toward Sustainable Development 25 February 2004. Denver, Colorado Victoria, British Columbia and L'Assomption, Quebec: Anthony Hodge Consultants Inc. (in press). Mining, Minerals and Sustainability. Chapter 3 in Dale, Ann (ed.) Industrial Ecology - Implications for Canada in the 21st Century. Vancouver: University of British Columbia Press.

Hodge, R.A., and I Taggart, 1992. Reporting on Sustainability: Human Well being within Ecosystem Well being. Unpublished Report prepared for the Policy and Research Committee, Ontario Round Table on Environment and Economy, Toronto, Ontario.

Hodge, Tony, Susan Holtz, Cameron Smith, and Kelly Hawke Baxter, 1995. Pathways to Sustainability: Assessing our Progress. Ottawa: National Round Table on the Environment and the Economy.

Joyce, Susan and Ian Thompson, 2000. Earning a Social License to Operate Social Acceptability and Resource Development in Latin America. Canadian Mining and Metallurgical Bulletin: 93: 1037, February 2000. Available on-line at http://www oncommonground.ca/publications/license.htm.

Mining Minerals and Sustainable Development, 2002a. Towards Change The Work and Results of MMSD - North America. Winnipeg: International Institute for Sustainable Development: Winnipeg. Available online at http://www.iisd.org/publications.asp

Mining Minerals and Sustainable Development, 2002b. Seven Questions to Sustainability - How to Assess the Contribution of Mining and Mineral Activities. International Institute for Sustainable Development: Winnipeg. Available on-line at http://www.iisd.org/publications.asp

Mumford, Lewis, 1934. "The Monastery and the Clock." Pp. 324 - 332 in D.L. Miller, 1986. The Lewis Mumford Reader. New York: Pantheon Books

NRCan, 2000. A Consultation Paper on Canadian Values Underlying the Sustainable Development of Minerals and Metals. Ottawa: Natural Resources Canada. Available on-line at http://www.nnrcan.gc.ca/mms/

NRTEE, 1993. Toward Reporting Progress on Sustainable Development in Canada - Report to the Prime Minister. Ottawa: National Round Table on the Environment and the Economy. Republished as Part I in Hodge, T., S. Holtz, C. Smith, and K. Hawke Baxter, 1995. Pathways to Sustainabil- ity: Assessing Our Progress. Ottawa: National Round Table on the Environment and the Economy.

NWMO, 2003. Asking the Right Questions? The Future Management of Canada's Used Nuclear Fuel. Toronto: Nuclear Waste Management Organization. Available on-line at http://www.nwmo.ca.

Placer Dome Inc., 2004. Building Momentum, PDG 2003 Annual Report. Vancouver: Placer Dome Inc. Available on-line at http://www.placerdome.com.

Prescott-Allen, Robert, 2001. The Wellbeing of Nations: A Country-byCountry Index of Quality of Life and the Environment. Washington: Island Press

Resource Science Inc., 2003. Business Plan, White Mountain Forestry Company, White Mountain Region Forest Restoration and Development: A Community-based Collaborative Forestry Approach for the Apache-Sitgreaves National Forest. Tucson, Arizona: Resource Science Inc.

Rio Tinto Borax, 2001. Borax and Sustainable Development. Internal draft report, Rio Tinto Borax, California.

Robinson, J. G., G. Francis, R. Legge, and S. Lerner, 1990. "Defining a sustainable society: values, principles, and definitions." Alternatives 17.2: $36-46$.

Runnalls, David, 2003. Sustainable Development and Nuclear Waste. NWMO Background Paper 1-1. Toronto: Nuclear Waste Mangement Organization. Available on-line at http://www.nwmo.ca.

SIL International, 2004. Ethnolgue: Languages of the World, 14th Edition. Dallas: SIL International, International Academic Bookstore. Available on-line at http://www.ethnologue.com/ethno_docs/distribution.asp.

Tahltan First Nation and the International Institute for Sustainable Development, 2004. Out of Respect - The Tahltan, Mining, and the Seven Questions to Sustainability. Report of the Tahltan Mining Symposium, April 4 - 6, 2003. Winnipeg, International Institute for Sustainable Development. Available on line at http://www.iisd.org/natres/mining

Tan Range Exploration Corporation, 2004. Business and Social Responsibility Overviews. Vancouver: Tan Range Exploration Corporation. Available on-line at http://www.tanrange.com/s/BusinessOverview.asp and http://www.tanrange.com/s/SocialResponsibility.asp

Thomson, Ian, 2003. Personal Communication. President, On Common Ground Consultants. Vancouver, British Columbia, Canada. See http://www.oncommonground.ca

UNCED, 1992. Agenda 21. United Nations Conference on Environment and Development. New York: United Nations

US Sustainable Minerals Roundtable, 2002. Summary of sustainable minerals indicators developed to date. Available on line at http://www.mackay.unr.edu/smr

WCED, 1987. Our Common Future. The World Commission on Environment and Development. Oxford: Oxford University Press.

West, Gerald, T, and E I. Tarazona, 2001. Investment Insurance and Development Impact. Washington D.C.: Multilateral Investment Guarantee Agency (MIGA)/World Bank Group.

Anthony Hodge is a geological engineer whose Ph.D. (1995, McGill) focussed on assessing progress toward sustainability. After working on groundwater and engineering geology projects in Africa and Central America, he served as Director of Research of the B.C. Royal Commission of Inquiry, Environment and Health Safety of Uranium Mining from 1978-1980. In 1987, he became the principal Canadian Researcher in a binational state-of-environment review of the Great Lakes region of North America. Through 2001 and 2002 he led a multi-interest US Canada review of practices in the mining/mineral industry (MMSDNorth America). In early 2003 he was appointed Senior Advisor to Canada's Nuclear Waste Management Organization.

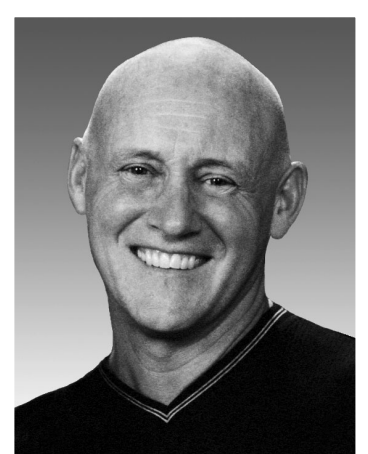

